\title{
Sex differences in retention of passive avoidance behavior in rats*
}

\author{
WILLIAM W. BEATTY, KENNETH C. GREGOIRE $\dagger$ \\ and LINDA L. PARMITER \\ North Dakota State Lniversity. Fargo, 1. Dak. 58102
}

Male and female rats were trained on a passive avoidance task that involved inhibition of an approach response rewarded by food. Rats of both sexes rapidly suppressed responding when punishment was initiated, but females resumed approach responding sooner than did males on nonshocked food-rewarded retention tests.

Recently, Denti \& Epstein (1972) reported that female rats retained passive avoidance behavior more poorly than did males. In their experiment, the rats were required to inhibit a spontaneous shut tling response that permitted the rat to escape from a lighted compartment into a darkened chamber. The present experiment was designed to assess the generality of the sex difference in passive avoidance behavior by examining performance under conditions where the approach response was rewarded by food.

\section{METHOD}

Animals

Twelve male and nine female experimentally naive Holtzman rats. 90-120 days old. were the Ss. They were caged singly in an air-conditioned animal room that was lighted from 9:00 a.m. $-9: 00$ p.m.

\section{Apparatus}

The apparatus was a $76 \times 4 \times 23$ in. high straight alley constructed of plastic and aluminum. At one end of the alley, a feeder, a foodcup. a rat lever, and a $15-\mathrm{W}$ red light were mounted on the wall. The alley was divided into six sections. The goalbox, 16 in. in length from the end of the alley that contained the feeder. had a floor made of $1 / 8$-in. bronze rods. The other five alley sections, each 12 in. long, had floors made of clear plastic. A guillotine door, made of Masonite, was located 64 in. from the foodcup and formed a 12-in.-long startbox. Scrambled electric shock could be delivered to the grid floor of the goalbox from a Grason Stadler E700 source.

\section{Procedure}

The rats were reduced to $80 \%$ of their free-feeding weights and kept at that level by food deprivation for the duration of the experiment. They were trained to barpress for $45-\mathrm{mg}$ Noyes pellets, initially in operant conditioning chambers and later in the alley goalbox. Next, the rats were given 10 sessions of approach training consisting of 10 trials per session. Each trial began when $\mathrm{E}$ raised the guillotine door, which started a timer. The rat's first barpress stopped the timer. On each trial, the rat was allowed to earn four $45-\mathrm{mg}$ Noyes pellets, presented on a CRF schedule. The intertrial interval was $10-15 \mathrm{sec}$.

On the day after the 10 th approach training session, passive avoidance training began. Each rat was first given two rewarded trials, as described above. On the next trial, the rat's first barpress was punished by a $1.0-\mathrm{mA}$ shock to the feet, which

\footnotetext{
*Partially supported by a grant from the North Dakota Institute for Regional Studies.

+ Now at the University of Nebraska, Lincoln, Nebr.
}

continued unt1l the rat escaped from the goalbox. For the next 60 sec. any subsequent barpress responses were similarly punished. If the rat had not administered two or more shocks by the end of the 67-sec period, the animal was placed onto the response bar and given a second shock by the E. One hour after passive avoidance acquisition, the rats were given a 5-min-long retention test. The shock was disconnected and the guillotine door was removed, but the bar and feeder were operative. The rat was placed into the fifth alley segment (farthest from goalbox). and its position in the alley was continuously monitored by an $O$. The latency of the first barpress and the number of barpresses were recorded. Similar retention tests were given on the next 3 days. During retention, each barpress was rewarded with a $45-\mathrm{mg}$ Noyes pellet.

\section{RESULTS}

Females ran slightly more slowly than males during the first four sessions of approach training, but the effect was not significant. Over the last six sessions, performance by both sexes was relatively stable and quite comparable; latencies from the raising of the door to the first barpress averaged about $5 \mathrm{sec}$.

Males and females acquired the passive avoidance response rapidly, and there was no sex difference. Two males received two self-initiated shocks during the $1-\mathrm{min}$ test: all other rats of both sexes earned one shock. However, sex differences were observed during the retention tests. Females returned to the bar earlier than males (median latency of the first barpress $=131 \mathrm{sec}$ for females and $511 \mathrm{sec}$ for males, $U=26, p=.05$ ). The poorer retention of the passive avoidance response by females was also evident in the distribution of time spent in the various segments of the alley on the first retention test, as shown in Fig. 1. Females spent a significantly greater percentage of time in the goalbox than did males $(U=23, p<.05)$ and a significantly smaller percentage of time in the fifth segment of the alley $(U=18$, $p<.02)$. On the second day, a similar, but

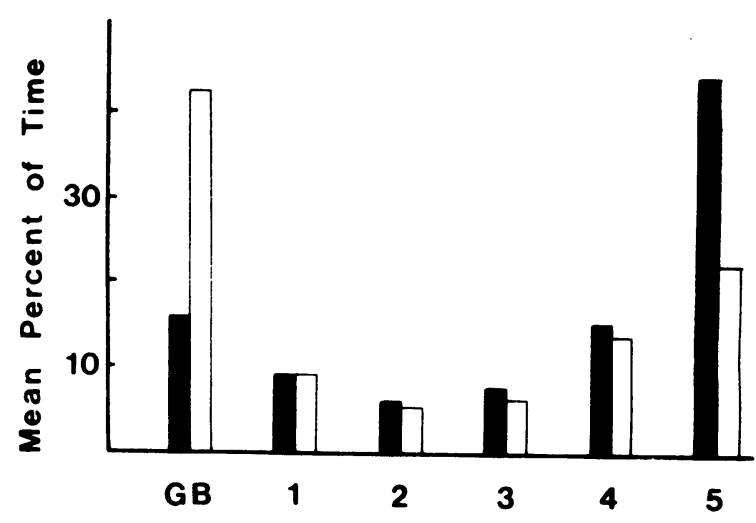

Fig. 1. Mean percentage of time spent in the goalbox (GB) and Alley Segments 1-5 (increasing distance from goalbox) on the first retention test. Black bars are males: white bars are females. 
nonsignificant, trend was observed on this measure. and on the third and fourth days. rats of both sexes spent approximately $80 \%$ of their time in the goalbox. Although females made somewhat more barpresses than males over the four retention tests, this difference was not statistically significant.

\section{DISCUSSION}

The present results are in close agreement with the results of Denti \& Epstein (1972). In both experiments females exhibited poorer retention of the passive avoidance response. Denti \& Epstein (1972) suggested that sex differences in gencral activity or exploration (e.g.. Denenberg \& Morton, 1962: Hitchcock. 1925) might underlie the sex difference in passive avoidance behavior. The present results are amenable to such an interpretation. since it is clear that sex differences in pain sensitivity (Beatty \& Beatty. 1970: Paré. 1969) cannot explain the poorer retention of the passive avoidance response by fimales and a sex difference in food motivation seems unlikely in view of the similar approach latencies observed.

\section{REFERENCES}

Beatty, W. W., \& Beatty, P. A. Hormonal determinants of sex differences in avoidance behavior and reactivity to electric shock in the rat. Journal of Comparative \& Physiological Psychology, 1970, 73, 446-455.

Denenberg, V. H. \& Morton, J. R. C. Effects of environmental complexity and social grouping upon modification of emotional behavior. Joumal of Comparative \& Physiological Psychology, 1962, 55, 242-246.

Denti, A \& Epstein, A. Sex differences in the acquisition of two kinds of avoidance behavior in rats. Physiology \& Behavior, $1972,8,611-615$.

Hitch cock, F. A. Studies in vigor: V. The comparative activity of male and female albino rats. American Journal of Physiology, 1925, 75, 205-210.

Paré, W. P. Age, sex, and strain differences in the aversive threshold to grid shock in the rat. Journal of Comparative \& Physiological Psychology, 1969, 69, 214-218.

(Received for publication June 4, 1973.) 